\title{
Estimation of Corrosion Rate of AISI 1016 Steel by the Analysis of Polarization Curves and Using the Method of Measuring Ohmic Resistance
}

\author{
K. V. Rybalka ${ }^{a}$ * , L. A. Beketaeva ${ }^{a}$, and A. D. Davydov ${ }^{a, ~ * *}$ \\ ${ }^{a}$ Frumkin Institute of Physical Chemistry and Electrochemistry, Russian Academy of Sciences, Moscow, 119071 Russia \\ *e-mail: mamaison2000@yandex.ru \\ **e-mail: alexdavydov@yandex.ru \\ Received October 11, 2019; revised February 6, 2020; accepted June 4, 2020
}

\begin{abstract}
By the example of the study of AISI 1016 steel corrosion in the $\mathrm{HCl}$ solution, the potentialities of various methods for determining the corrosion currents are studied. The corrosion rate of steel without polarization is determined using the method of measuring ohmic resistance of test specimen. It is shown that the iterative method used for the analysis of potentiodynamic curves in the vicinity of corrosion potential avoids the complications that arise when the Tafel extrapolation method is used in the absence of pronounced Tafel sections in these curves.
\end{abstract}

Keywords: stainless steel, corrosion current, ohmic resistance, Tafel extrapolation, iterative method DOI: $10.1134 / \mathrm{S} 1023193521010092$

\section{INTRODUCTION}

The Tafel extrapolation method is widely used in the electrochemical practice for determining the corrosion rate of metals [1-12]. Its main advantage is the ability of rapid determination of corrosion current. The possibility to investigate both actively corroding and corrosion-resistant materials is also an undoubted advantage of this method. At the same time, a number of limitations of this method should be indicated. The method assumes that only one reaction proceeds in the potential range under consideration. Thus, strictly speaking, the equations underlying the method may be inapplicable to the study of alloys [1-3] and in the case that the system under investigation contains several depolarizers (for example, hydrogen ions and dissolved oxygen). In addition, for precise determination of corrosion current, it is necessary that the linear section in the experimental curve covers at least one order of magnitude of current [2]. However, this requirement is not always met in practice. The Tafel extrapolation method can be inapplicable due to the absence of well defined linear section in the polarization curves. In [3], the corrosion rates of several electrochemical systems, which were determined by the Tafel extrapolation method and several independent methods, were compared, and the corrosion rates appeared to be rather close. In [4], the corrosion rate of carbon steel in the $\mathrm{HCl}$ solutions was determined by the Tafel extrapolation method, the gravimetric method, and the analysis of solution. It was shown that, in the given examples, the corrosion rates, which were determined by the gravimetric method and the analysis of solution, were in good agreement. The corrosion rate, which was determined by the Tafel extrapolation method, turned out to be much higher in this case. For the $1 \mathrm{M} \mathrm{HCl}$ solution, the rates differed by more than 5 times. The authors of [4] indicated the advantages of the Tafel method for rapid determination of corrosion rate; however, they believe that the results obtained by the Tafel method should be simultaneously compared with the data obtained by the gravimetric method.

When a pronounced Tafel section is observed only in one, cathodic or anodic, branch of polarization curve, only this curve section may be extrapolated $[3,6]$. In these cases, more frequently, the Tafel curve sections are observed in the cathodic branch.

The Tafel sections characterize the kinetics of only one, cathodic or anodic, reaction, because they lie at such a distance from the corrosion potential $E_{\text {corr }}$ that the reaction, which is not the main one in the given potential range, can be neglected. A large distance from the Tafel curve section to $E_{\text {corr }}$ can lead to an error in the determined corrosion current due to a possible difference in the surface state between this area and that at $E_{\text {corr }}[6,11]$. The polarization curve sections in the vicinity of $E_{\text {corr }}$ correspond to the concurrent cathodic and anodic reactions.

The method of polarization resistance involves the determination of the slope of linear sections of polar- 
ization curves adjacent to $E_{\text {corr }}$ in the potential range within $\pm 10 \mathrm{mV} \mathrm{[6].} \mathrm{However,} \mathrm{the} \mathrm{corrosion} \mathrm{current}$ density can be determined from the polarization resistance provided that the anodic and cathodic Tafel slopes are known.

In some works $[10,11]$, the corrosion current density was determined by measuring simultaneously the polarization resistance and the Tafel slopes in the analysis of the sections of polarization curves in the potential range, where the curves are linear, and a certain initial nonlinear curve section. The results were analyzed using the fitting method.

In this work, by the example of the study of corrosion behavior of AISI 1016 steel in the $0.1 \mathrm{M} \mathrm{HCl}$ solution, the potentialities of the Tafel extrapolation method and an independent method for determining the corrosion rate, the method of measuring ohmic resistance of test specimen, are compared. The potentialities of the iterative method, as an alternative to the Tafel method in the cases that no Tafel sections are observed in the polarization curves, are also considered.

\section{EXPERIMENTAL PROCEDURE}

The specimens of AISI 1016 steel wire $0.8 \mathrm{~mm}$ in diameter were studied. Table 1 lists the chemical composition of steel.

All measurements were performed in the $0.1 \mathrm{M}$ $\mathrm{HCl}$ (ultra-high purity grade) solution in twice-distilled water with free air access at a temperature of $25^{\circ} \mathrm{C}$. The test specimens were preliminarily kept in the working solution for $48 \mathrm{~h}$ to stabilize their surface conditions. The specimen potential was measured against a saturated silver chloride electrode.

The potentiodynamic curves were recorded with a potential scan rate of $1 \mathrm{mV} / \mathrm{s}$. Both under the anodic and cathodic polarization, the measurements started from the corrosion potential. The polarization of wire specimen was performed with an IPC2000 Pro potentiostat (EKONIKS, Russia) both in the potentiodynamic measurements and in the study by the method of measuring ohmic resistance. In the latter case, the test specimen was kept at a given potential and the current was simultaneously recorded. Then, a charge $Q$ consumed during the polarization was determined by integrating the current. Prior to the polarization and after its completion, the specimen resistance was measured and a change in the wire radius under the anodic polarization was calculated. Based on these data, taking into account the specimen density, the amount of dissolved metal was determined.

When measuring the resistance of the test specimen, a preassigned current, which is generated by a $\mathrm{BP}-49 \mathrm{dc}$ power source, is divided into two equal parts passing through identical resistors (their resistance is by three orders of magnitude higher than that of the test specimen). Both components of the current pass
Table 1. Chemical composition of AISI 1016 steel

\begin{tabular}{l|c|c|c|c|c}
\hline Element & $\mathrm{C}$ & $\mathrm{Mn}$ & $\mathrm{P}$ & $\mathrm{S}$ & $\mathrm{Fe}$ \\
\hline wt \% & $0.13-0.18$ & $0.60-0.90$ & $\leq 0.040$ & $\leq 0.050$ & $>98$ \\
\hline
\end{tabular}

through the test specimen, which is placed into the vessel with the electrolyte, and through an auxiliary resistor similar to the test specimen, which is located on the outer surface of the vessel. The currents, which pass through the test specimen and the auxiliary resistor, are opposite in directions. As a result, the potential differences across the test specimen and the auxiliary resistor compensate each other. This allows one to measure small changes in the resistance of the test specimen, which are caused by a decrease in its diameter in the course of corrosion. The potential difference is measured with a V7-21A universal voltmeter. Knowing the change in the potential difference $\Delta u(t)$ and the current $i$, it is easy to determine the variation of the resistance of specimen immersed into the electrolyte with time $\Delta R(t)=\Delta u(t) / i$. The dependence of wire radius $r(t)$ on the time it is kept in the electrolyte is as follows:

$$
r(t)=\left[\frac{1}{r_{0}^{2}}+\frac{\pi \Delta R(t)}{\rho L}\right]^{-1 / 2}
$$

where $r_{0}$ is the initial wire radius, $L$ is its length, $\Delta R(t)$ is a change in its resistance due to corrosion, and $\rho$ is the specific resistance of steel. Knowing the change in the wire radius, a decrease of the specimen weight $\Delta M$ in this period of time can be easily calculated:

$$
\Delta M=\pi\left(r_{1}^{2}-r_{2}^{2}\right) L g,
$$

where $r_{1}$ and $r_{2}$ are the wire radii at the beginning and at the end of polarization, $L$ is the specimen length, and $g$ is the metal density, $7.7 \mathrm{~g} / \mathrm{cm}^{3}$. The procedure of specimen resistance measurement and calculations was described in detail earlier [13].

\section{RESULTS AND DISCUSSION}

Figure 1 shows the cathodic and anodic polarization curves measured in the $0.1 \mathrm{M} \mathrm{HCl}$ solution.

A well-defined linear section, which covers the current changing by an order of magnitude, is observed in the anodic curve. No linear section can be recognized in the cathodic curve; such polarization curves frequently occur in the electrochemical practice. This may be associated with the diffusion of depolarizer [14] or with simultaneous reduction of dissolved oxygen and hydrogen ions at the electrode [15]. In this case, equation (3)

$$
i=i_{\text {corr }}\left[\exp \left(\frac{E-E_{\text {corr }}}{b_{\mathrm{c}}}\right)-\exp \left(\frac{E_{\text {corr }}-E}{b_{\mathrm{a}}}\right)\right]
$$




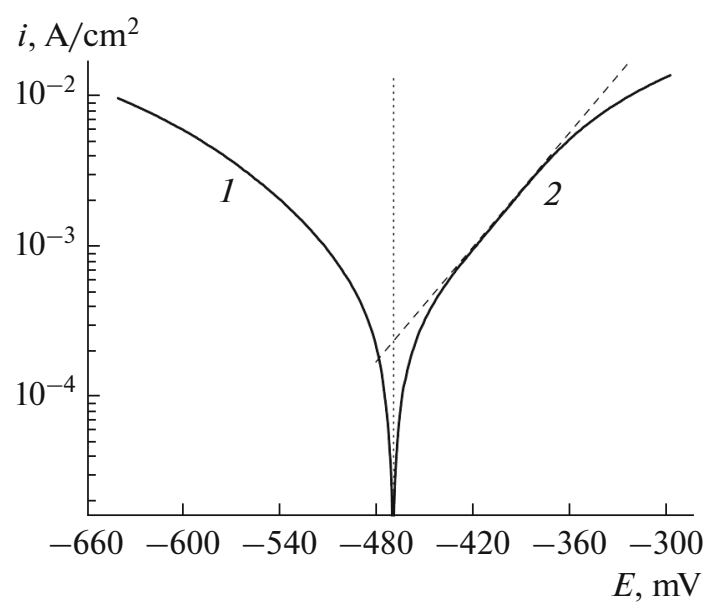

Fig. 1. (1) Cathodic and (2) anodic potentiodynamic curves (the potential scan rate is $1 \mathrm{mV} / \mathrm{s}$ ) measured on AISI 1016 steel in $0.1 \mathrm{M} \mathrm{HCl}$ solution.

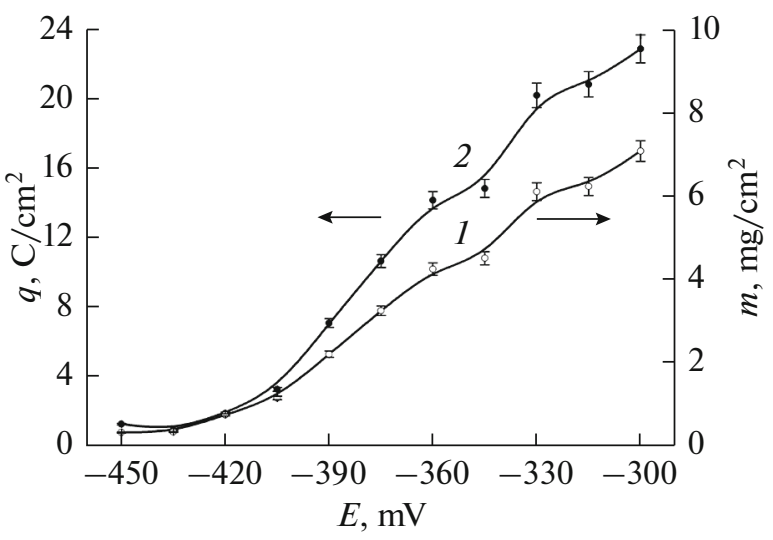

Fig. 2. Dependences of (1) the weight of AISI 1016 steel dissolved in $0.1 \mathrm{M} \mathrm{HCl}$ and (2) the charge on the potential. At each potential, the polarization is performed for $1 \mathrm{~h}$.

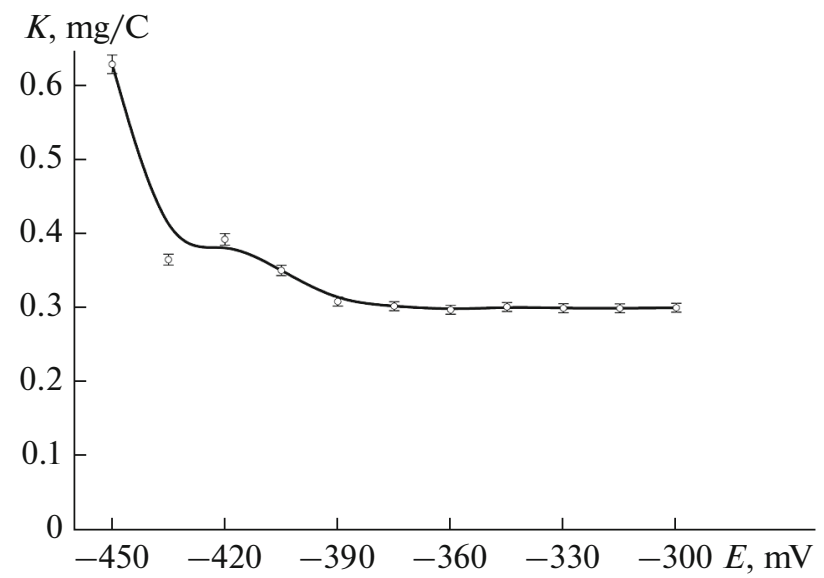

Fig. 3. Dependence of experimentally determined electrochemical equivalent of AISI 1016 steel on the potential. which underlies the Tafel extrapolation method for determining the corrosion rate [6], is obviously inapplicable.

As follows from Fig. 1, the extrapolation of pronounced linear section in the anodic curve to the corrosion potential yields a corrosion current of $2.4 \times$ $10^{-4} \mathrm{~A} / \mathrm{cm}^{2}$.

Simultaneously, the corrosion current was determined by an independent method, the method of measuring ohmic resistance, which can be considered as a kind of the gravimetric method for determining the corrosion rate. At the same time, the method of measuring ohmic resistance differs from the conventional gravimetric method in that the reaction products, which are accumulated on the surface of the test specimen, have no effect on the result, obviously, if their conductivity is significantly lower than that of the metal under investigation. This method enables one to monitor the variation of the specimen corrosion rate over a long period of time without removing it from the solution.

Figure 2 shows the dependences of the weight of dissolved AISI 1016 steel, which were obtained by the method of measuring specimen ohmic resistance, and the consumed charge on the potential.

The charge is calculated by integrating the $i$ vs. $t$ curves that were measured under the polarization of the specimen. In all cases, the polarization was performed for $1 \mathrm{~h}$.

The ratio between the weight $\Delta M$ of steel dissolved under polarization at a prescribed potential and the charge $\Delta Q$ consumed for its dissolution enables us to determine the electrochemical equivalent of steel $K=$ $\Delta M / \Delta Q$. Figure 3 shows the dependence of electrochemical equivalent of steel on the potential. An inflection near a potential of $-435 \mathrm{mV}$, probably, is associated with the fact that this is a transition region, where the anodic and cathodic components of the total current are close in magnitude; then, the cathodic component decreases and the current becomes completely anodic.

Thus determined electrochemical equivalent of AISI 1016 steel $(0.29 \mathrm{mg} / \mathrm{C})$, which contains more than $98 \%$ iron in its composition, agrees well with the electrochemical equivalent for pure iron $(0.289 \mathrm{mg} / \mathrm{C})$ [16]. The electrochemical equivalent is kept constant for the potentials above $-360 \mathrm{mV}$. At more negative potentials, the electrochemical equivalent increases. This is caused by the contribution of the cathodic component of polarization current. As a result, the charge $\Delta Q$, by which the change in the weight $\Delta M$ should be divided to determine the equivalent, is underestimated and the electrochemical equivalent obtained in this way does not correspond to the real value.

Figure 4 shows the dependence of the dissolution rate of AISI 1016 steel on the potential (including the corrosion potential of $-466 \mathrm{mV}$ ) that is determined by the method of measuring resistance. It is seen that the 


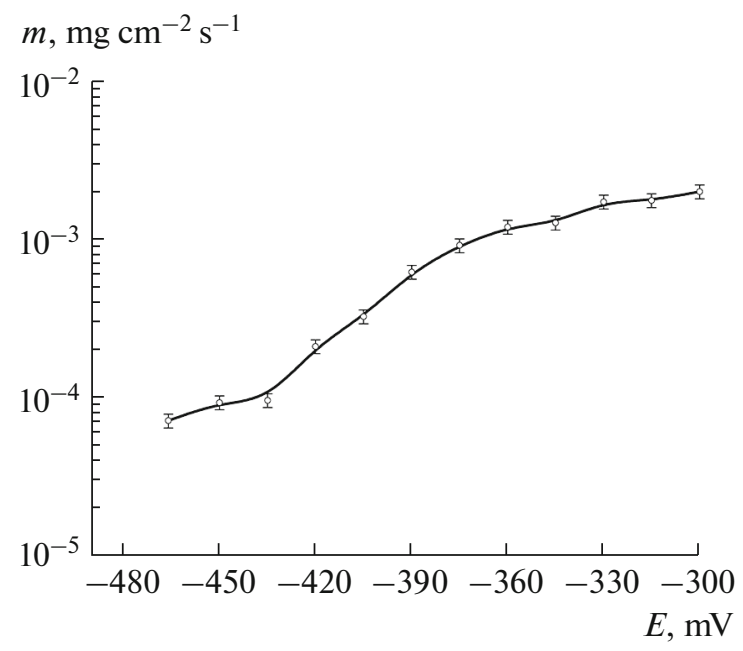

Fig. 4. Dependence of AISI 1016 steel dissolution rate on the potential.

steel dissolution rate at the corrosion potential is $7.1 \times$ $10^{-5} \mathrm{mg} \mathrm{cm}^{-2} \mathrm{~s}^{-1}$. In order to compare the results obtained by this method with the corrosion current determined from the data shown in Fig. 1, the anodic dissolution rate (Fig. 4) is converted into the electrical units using the electrochemical equivalent obtained for the steel under investigation. Thus obtained corrosion current is $2.4 \times 10^{-4} \mathrm{~A} / \mathrm{cm}^{2}$. The current determined by the method of measuring ohmic resistance is independent of any assumptions about the mechanism of the processes on the specimen surface.

The absence of a well-defined linear section in the cathodic curve points to the inapplicability of equation (3) and, correspondingly, the Tafel extrapolation method for determining the corrosion current. This shape of the curve may be due to the effect of mass transfer in the cathodic potential range. Equation (4) enables calculating the corrosion current, when the electrochemical process proceeds in the mixed mode, taking into account the effect of the depolarizer diffusion $\left(i_{\mathrm{d}}\right)$ on the cathodic process [17]. Equation (4) takes into consideration one cathodic reaction. In the case of two cathodic reactions (the reduction of oxygen dissolved in the electrolyte and hydroxonium ions), as it was shown earlier [15], two pronounced linear sections are observed in the cathodic curve. In our case, when a dilute acid solution is used, probably, the oxygen reduction is the prevailing cathodic reaction. This reaction is taken into account in equation (4):

$$
\begin{gathered}
i=i_{\text {corr }} \exp \left(\frac{E-E_{\text {corr }}}{b_{\mathrm{a}}}\right) \\
-\frac{i_{\text {corr }} i_{\mathrm{d}} \exp \left(\frac{E_{\mathrm{corr}}-E}{b_{\mathrm{c}}}\right)}{i_{\mathrm{d}}-i_{\text {corr }}+i_{\text {corr }} \exp \left(\frac{E_{\mathrm{corr}}-E}{b_{\mathrm{c}}}\right)} .
\end{gathered}
$$

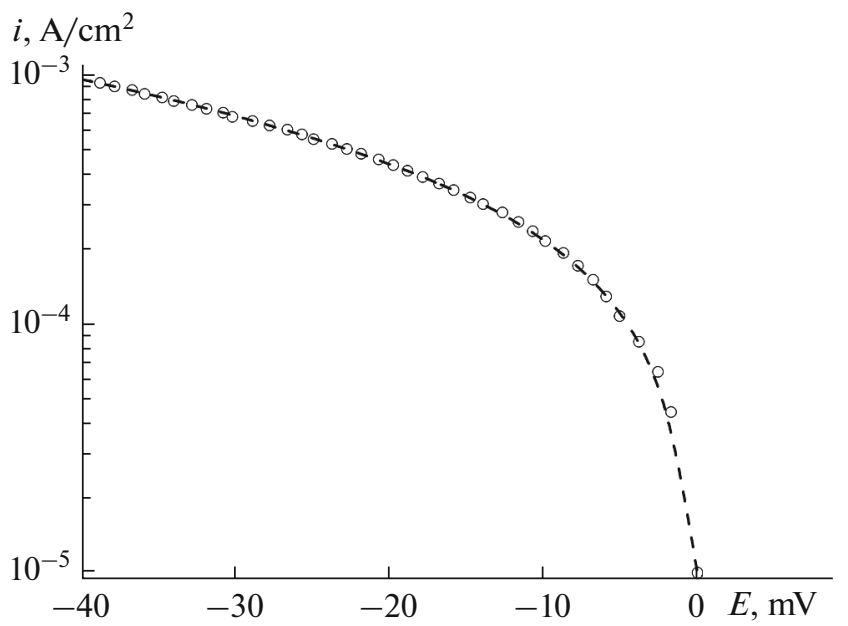

Fig. 5. Dependence of current density in the polarization of AISI 1016 steel electrode in $0.1 \mathrm{M} \mathrm{HCl}$ solution on the potential: the experimental data are shown with open circles and the calculated data are shown with a dashed line.

Figure 5 shows the experimental cathodic curve (Fig. 1, curve 1) and the curve calculated by equation (4). The parameters in the vicinity of corrosion potential are calculated by the iterative method using the genfit function of the MATHCAD software [14].

As follows from Fig. 5, the experimental and calculated curves completely coincide in the potential range under consideration. The cathodic potential range near the corrosion potential contains information on both the cathodic process, which proceeds at the electrode, and the anodic process of alloy dissolution. The corrosion current density, which is determined in this potential range by the iterative method, is $2.46 \times 10^{-4} \mathrm{~A} / \mathrm{cm}^{2}, \beta_{\mathrm{a}}=2.3 b_{\mathrm{a}}=44 \mathrm{mV} /$ decade and $\beta_{\mathrm{c}}=2.3 b_{\mathrm{c}}=52 \mathrm{mV} /$ decade.

The corrosion current, which is determined by this method, differs by less than $2 \%$ from that determined by the method of measuring resistance $\left(2.4 \times 10^{-4} \mathrm{~A} / \mathrm{cm}^{2}\right)$ and by the method of extrapolation of anodic curve $\left(2.4 \times 10^{-4} \mathrm{~A} / \mathrm{cm}^{2}\right)$.

The same value of corrosion current was obtained taking into account equation (4) using the iterative method in the potential range containing cathodic and anodic curves (Fig. 6) in the vicinity of corrosion potential (from -40 to $40 \mathrm{mV}$ ).

The corrosion current density, which is calculated from the data presented on Fig. 6 , is $2.46 \times 10^{-4} \mathrm{~A} / \mathrm{cm}^{2}$, $\beta_{\mathrm{a}}$ is $91 \mathrm{mV} /$ decade and $\beta_{\mathrm{c}}$ is $52 \mathrm{mV} /$ decade. The corrosion currents and coefficients $\beta_{\mathrm{c}}$, which are calculated using only cathodic curve and both curves in the vicinity of corrosion potential, coincide. The coefficient $\beta_{\mathrm{a}}$, which is obtained from the data presented in Fig. 6, appeared to be two times higher than that determined by only cathodic curve. This can be explained by the fact that the analysis of only cathodic curve 
Table 2. Parameters of corrosion process determined by various methods

\begin{tabular}{l|c|c|c|c}
\hline \multicolumn{1}{c|}{ Parameter } & $\begin{array}{c}\text { Method of ohmic } \\
\text { resistance }\end{array}$ & $\begin{array}{c}\text { Tafel method, } \\
\text { anodic curve }\end{array}$ & $\begin{array}{c}\text { Iterative method, } \\
\text { cathodic curve }\end{array}$ & $\begin{array}{c}\text { Iterative method, } \\
\text { both curves }\end{array}$ \\
\hline$i_{\text {corr }}, \mathrm{A} / \mathrm{cm}^{2}$ & $2.4 \times 10^{-4}$ & $2.4 \times 10^{-4}$ & $2.46 \times 10^{-4}$ & $2.46 \times 10^{-4}$ \\
$\beta_{\mathrm{c}}, \mathrm{mV}$ & & 78 & 52 & 52 \\
$\beta_{\mathrm{a}}, \mathrm{mV}$ & & 44 & 91 \\
\hline
\end{tabular}

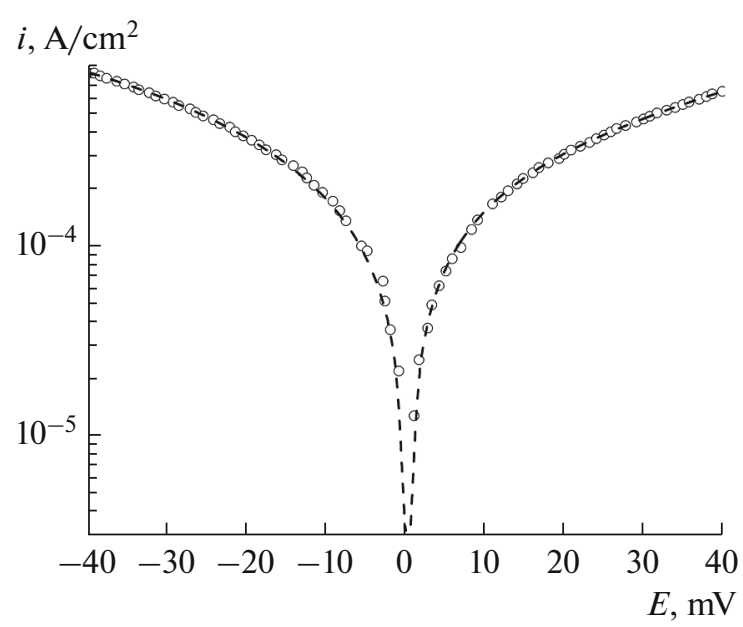

Fig. 6. Dependence of current density in the polarization of AISI 1016 steel electrode in $0.1 \mathrm{M} \mathrm{HCl}$ solution on the potential: the experimental data are shown with open circles and the calculated data are shown with a dashed line.

gives insufficient information about the anodic process for accurate determination of $\beta_{\mathrm{a}}$. Table 2 lists the calculated parameters of corrosion process.

The results show that, even in the absence of pronounced linear sections in the polarization curve, taking into account the mass transfer of the depolarizer, one can determine the corrosion current using the iterative method.

\section{CONCLUSIONS}

The electrochemical equivalent of AISI 1016 steel was determined experimentally $(0.29 \mathrm{mg} / \mathrm{C})$. It appeared to be very close to the electrochemical equivalent of iron dissolved in the form of $\mathrm{Fe}^{2+}$ compound $(0.289 \mathrm{mg} / \mathrm{C})$.

The corrosion rate of steel in the absence of specimen polarization was determined by the method of measuring ohmic resistance; in the electric units, it is $2.4 \times 10^{-4} \mathrm{~A} / \mathrm{cm}^{2}$.

The analysis of anodic and cathodic polarization curves in a wide potential range shows that only anodic curve contains the Tafel section. By extrapolating this curve section to the corrosion potential, the corrosion current of $2.4 \times 10^{-4} \mathrm{~A} / \mathrm{cm}^{2}$ is obtained.

No Tafel section is observed in the cathodic polarization curve. The cathodic polarization curve, which is calculated using the equation for determining the corrosion current under the conditions of mixed kinetics in the vicinity of corrosion potential and the iterative method, almost coincides with the experimental cathodic polarization curve. Thus obtained corrosion current density is $2.46 \times 10^{-4} \mathrm{~A} / \mathrm{cm}^{2}$. It differs from the corrosion current density obtained by extrapolating anodic Tafel curve section and using the method of ohmic resistance by less than $2 \%$.

\section{FUNDING}

The work was performed with support of Ministry of Science and Higher Education of Russian Federation.

\section{CONFLICT OF INTEREST}

The authors declare that they have no conflicts of interest.

\section{OPEN ACCESS}

This article is distributed under the terms of the Creative Commons Attribution 4.0 International Public License (http://creativecommons.org/licenses/by/4.0/), which permits unrestricted use, distribution, and reproduction in any medium provided you give appropriate credit to the original author(s) and the source, provide a link to the Creative Commons license, and indicate if changes were made.

\section{REFERENCES}

1. Gileadi, E. and Kirowa-Eisner, E., Some observations concerning the Tafel equation and its relevance to charge transfer in corrosion, Corros. Sci., 2005, vol. 47, p. 3068.

2. Harvey, J., Flitt, D., and Schweinsberg, P., A guide to polarization curve interpretation: deconstruction of experimental curves typical of the $\mathrm{Fe} / \mathrm{H}_{2} \mathrm{O} / \mathrm{H}^{+} / \mathrm{O}_{2}$ corrosion system, Corros. Sci., 2005, vol. 47, p. 2125.

3. McCafferty, E., Validation of corrosion rates measured by the Tafel extrapolation method, Corros. Sci., 2005, vol. 47 , p. 3202. 
4. Poorqasemi, E., Abootalebi, O., Peikari, M., and Haqdar, F., Investigating accuracy of the Tafel extrapolation method in $\mathrm{HCl}$ solutions, Corros. Sci., 2009, vol. 51, p. 1043.

5. Mansfeld, F., The polarization resistance technique for measuring corrosion currents, in Advances in Corrosion Science and Technology, Fontana, G. and Staehle, R.W., Eds., New York: Plenum, 1976, vol. 6, ch. 2, p. 163.

6. Kaesche, H., Die Korrosion der Metalle, Berlin: Springer, 1979.

7. Stansbury, E.E. and Buchanan, R.A., Fundamentals of the Electrochemical Corrosion, Materials Park, Ohio: ASM Int., 2000, ch. 6.

8. McCafferty, E., Introduction to Corrosion Science, New York: Springer, 2010, ch. 7.

9. Kelly, R.G., Scully, J.R., Shoesmith, D.W., and Buchheit, R.G., Electrochemical Techniques in Corrosion Science and Engineering. New York: Marcel Dekker, 2003, ch. 2.

10. Oldham, K.B. and Mansfeld, F., Corrosion rates from polarization curves: a new method, Corros. Sci., 1973, vol. 13, p. 813.

11. Mansfeld, F., Simultaneous determination of instantaneous corrosion rates and Tafel slopes from polarization resistance measurements, J. Electrochem. Soc., 1973, vol. 120, p. 515.
12. Rybalka, K.V., Beketaeva, L.A., and Davydov, A.D., Estimation of corrosion current by the analysis of polarization curves: electrochemical kinetics mode, Russ. J. Electrochem., 2014, vol. 50, p. 108.

13. Rybalka, K.V., Beketaeva, L.A., and Davydov, A.D., Determination of AISI 304 steel corrosion rate in the $\mathrm{HCl}$ solutions by the method of measuring specimen ohmic resistance, Russ. J. Electrochem., 2019, vol. 55, p. 920.

14. Rybalka, K.V., Beketaeva, L.A., and Davydov, A.D., Determination of corrosion current in general corrosion under the conditions of mixed kinetics, Russ. J. Electrochem., 2014, vol. 50, p. 390.

15. Rybalka, K.V., Beketaeva, L.A., and Davydov, A.D., Cathodic component of corrosion process: polarization curve with two Tafel portions, Russ. J. Electrochem., 2018, vol. 54, p. 456.

16. Hering, C. and Getmah, F.H., Standard Table of Electrochemical Equivalents and Their Derivatives, New York, 1917.

17. Nagy, Z. and Thomas, D.A., Effect of mass transport on the determination of corrosion rates from polarization measurements, J. Electrochem. Soc., 1986, vol. 133, p. 2013.

Translated by T. Kabanova 